\title{
PENGARUH PENGGUNAAN AFO FLEKSIBEL DAN AFO JOINTED PLANTAR FLEKSI STOP TERHADAP KECEPATAN BERJALAN PASIEN DENGAN HEMIPARETIC CEREBROVASCULAR ACCIDENT ( CVA )
}

\author{
Agus Setyo Nugroho, M.Syafi'i, Sri Surini Pudjiastuti \\ Kementerian Kesehatan Politeknik Kesehatan Surakarta Jurusan Ortotik Prostetik
}

\begin{abstract}
Drop Foot, AFO Fleksibel, AFO Jointed Plantar Stop, Walking Speed, $\boldsymbol{C V A}$. Research Objectives To determine whether there is a difference in the use of AFO Flexible and AFO Jointed Plantar Stop against the walking speed of someone who has drop foot because of CVA. The experimental quasy research method used two group pre and post test design approach. The study population was patients who had drop foot because of CVA. Statistical test result with paired t test at Flexible AFO user group walking speed shows $p$ value 0,000 <0,05 so there is Flexible AFO effect to different speed of walking in drop foot sufferer. Result of statistical test with paired t test at walk time of user group of AFO Jointed Plantar Stop shows p value 0,000<0,05 so there is influence of AFO Jointed Plantar Stop to difference of walking time in patient of drop foot. Statistical test results with paired t test at the walking speed of AFO Jointed Plantar Stop user group showed p value 0,000<0,05 so that there is influence of AFO Jointed Plantar Stop to difference of walking speed in drop foot sufferer. The result of statistical test with paired t test at walk time of AFO Flexible user group with AFO Jointed Plantar Stop shows p value 0,013<0,05 so there is time difference walking using AFO Flexible with AFO Jointed Plantar Stop on walking time in drop foot sufferer. The result of statistical test with paired t test at Flexible AFO user group speed with AFO Jointed Plantar Stop shows p value 0,012<0,05 so there is difference of walking speed using AFO Flexible with AFO Jointed Plantar Stop to walking speed at patient of foot foot.Dengan Conclusion The use of AFO Flexible has a better walkspeed effect compared to the use of AFO Jointed plantar stop with an average difference of 0.010
\end{abstract}

Keywords: Drop Foot, AFO Fleksibel, AFO Jointed Plantar Stop, Walking Speed, CVA

Abstrak : Drop Foot, AFO Fleksibel, AFO Jointed Plantar Stop, Kecepatan
berjalan, CVA. Tujuan Penelitian Mengetahui apakah terdapat perbedaan dalam
penggunaan AFO Fleksibel dan AFO Jointed Plantar Stop terhadap kecepatan berjalan
pada seseorang yang mengalami drop foot oleh karena CVA. Dengan Metode Penelitian
quasy eksperimental menggunakan pendekatan rancangan two group pre and post test
design. Populasi penelitian adalah pasien yang mengalami drop foot oleh karena CVA.
Hasil uji Statistik dengan t test berpasangan pada kecepatan berjalan kelompok
pengguna AFO Fleksibel menunjukkan $p$ value $0,000<0,05$ sehingga terdapat pengaruh
AFO Fleksibel terhadap perbedaan kecepatan berjalan pada penderita drop foot. Hasil
uji statistik dengan t test berpasangan pada waktu berjalan kelompok pengguna $A F O$
Jointed Plantar Stop menunjukkan $p$ value $0,000<0,05$ sehingga terdapat pengaruh 
AFO Jointed Plantar Stop terhadap perbedaan waktu berjalan pada penderita drop foot. Hasil uji Statistik dengan $\mathrm{t}$ test berpasangan pada kecepatan berjalan kelompok pengguna AFO Jointed Plantar Stop menunjukkan $p$ value $0,000<0,05$ sehingga terdapat pengaruh AFO Jointed Plantar Stop terhadap perbedaan kecepatan berjalan pada penderita drop foot. Hasil uji statistik dengan t test berpasangan pada waktu berjalan kelompok pengguna AFO Fleksibel dengan AFO Jointed Plantar Stop menunjukkan $p$ value $0,013<0,05$ sehingga terdapat perbedaan waktu berjalan menggunakan AFO Fleksibel dengan AFO Jointed Plantar Stop terhadap waktu berjalan pada penderita drop foot. Hasil uji statistik dengan t test berpasangan pada kecepatan berjalan kelompok pengguna AFO Fleksibel dengan AFO Jointed Plantar Stop menunjukkan $p$ value $0,012<0,05$ sehingga terdapat perbedaan kecepatan berjalan menggunakan AFO Fleksibel dengan AFO Jointed Plantar Stop terhadap kecepatan berjalan pada penderita drop foot. Dengan Kesimpulan penggunaan AFO Fleksibel memiliki pengaruh kecepatan berjalan lebih bagus dibandingkan dengan penggunaan AFO Jointed plantar stop dengan perbedaan rata-rata kecepan sebesar 0,010

Kata Kunci : Drop Foot, AFO Fleksibel, AFO Jointed Plantar Stop, Kecepatan Berjalan, CVA

\section{PENDAHULUAN}

Stroke adalah masalah neurlogik primer di Amerika Serikat dan di Dunia. Meskipun upaya pencegahan telah menimbulkan penuwalkan pada kejadian beberapa tahun terakhir, Stroke peringkat ketiga penyebab kematian, dengan laju mortalitas $18 \%$ sampai $37 \%$ untuk stroke pertama dan sebesar $62 \%$ untuk stroke selanjutnya. Terdapat kira-kira 2 juta orang pertahan hidup dari stroke yang mempunyai beberapa kecacatan dari angka $40 \%$ memerlukan bantuan dalam aktifitas sehari-hari (Bwalkener \& Suddarth, 2002). Stroke merupakan penyakit sistem persarafan yang paling sering di jumpai kira-kira 200.000 kematian dan 200.000 orang dengan gejala sisa akibat stroke pada setiap umur, tetapi yang paling sering pada usia 75-85 tahun. Pada setiap bagian ini terminologi CVA akan dipakai sebagai istilah umum. Banyak ahli saraf dan bedah saraf menyatakan penyebab CVA paling sering adalah Trombosis, emboli, dan hemoragik. Stroke dapat didahului oleh beberapa faktor pencetus dan sering kali yang berhubungan dengan penyakit kronis yang menyebabkan misalnya penyakit vaskular termasuk penyakit jantung, hipertensi, diabetes, obesitas, kolesterol, merokok, stress, dan gaya hidup (Muttaqin, 2008).

World Health Organisation (WHO) menyatakan bahwa sekitar 5, 5 juta orang di dunia meninggal akibat stroke pada tahun 2002 (Juniarti, 2008). Konferensi Stroke Internasional tahun 2008 yang diadakan di Wina, Austria, mengungkapkan bahwa jumlah kasus stroke di kawasan Asia terus meningkat (Jurnal Stroke, 2010). Projodisastro (2009) dalam Juniarti (2008) memperkirakan penyakit jantung dan stroke akan menjadi penyebab utama kematian di dunia pada tahun 2020. Selain itu, WHO (2004) dalam Aziz et al (2008) memprediksi bahwa jumlah kasus stroke akan meningkat sehubungan dengan peningkatan trend dalam populasi lanjut 
usia di seluruh dunia.

Data stroke yang dikeluarkan oleh Yayasan Stroke Indonesia menyatakan bahwa penderita stroke di Indonesia jumlahnya terus meningkat dari tahun ke tahun (Jurnal Stroke, 2010). Berdasarkan penelitian Riset Kesehatan Dasar tahun 2007 di 33 provinsi dan 440 kabupaten di Indonesia diperoleh hasil bahwa penyakit stroke merupakan pembunuh utama di kalangan penduduk perkotaan (Riskesdas, 2007). Secara kasar, setiap hari ada dua orang Indonesia mengalami serangan stroke.

Gejala stroke dapat bersifat fisik, psikologis dan perilaku. Gejala fisik yang paling khas adalah paralisis, kelemahan, hilangnya sensasi diwajah, lengan atau tungkai disalah satu sisi tubuh, kesulitan berbicara, kesulitan menelan dan hilangnya sebagian penglihatan disatu sisi. Seorang dikatakan terkena stroke jika salah satu atau kombinasi apapun dari gejala diatas berlangsung selama 24 jam atau lebih (Feigin, 2007).

Dalam beberapa pembelajaran mengenai Ankle Foor Orthosis ( AFO ) menunjukan bahwa AFO Fleksibel mempunya indikasi digunakan untuk drop foot dengan spasticity sedang, serta kontra indikasi berupa medio-lateral insstability, odema, serta knee hyperextensi. AFO Fleksibel mempunyai keuntungan berupa pergerakan pada ankle masih memungkinkan terjadi, Praktis untuk dipakai, kosmetiknya bagus serta sesuai dengan sepatu yang akan digunakan. $A F O$ Jointer Platar Fleksi Stop mempunyai indikasi digunakan pada drop foot, knee hyperekstensi pada saat stance serta kontra indikasi berupa pola berjalan fleksi, ketika dorsi fleksi dapat menimbulakn Subtalar joint dan midfoot Collapse, pasien memiliki kelemahan pada otot sisi proksimal, adanya oedema. AFO Jointed Plantar Fleksi Stop Memiliki kelebihan berupa dapat memungkinkan tibia lebih kedepan pada saat berdiri serta menghilangkan hrperextensi moment dari rigid AFO.

\section{METODE PENELITIAN}

Metode Penelitian ini menggunakan quasy eksperimental dengan pendekatan rancangan two group pre and post test design. Populasi penelitian adalah pasien yang mengalami drop foot oleh karena CVA. Hasil uji Statistik dengan $t$ test berpasangan pada kecepatan berjalan kelompok pengguna AFO Fleksibel menunjukkan $p$ value $0,000<0,05$ sehingga terdapat pengaruh AFO Fleksibel terhadap perbedaan kecepatan berjalan pada penderita drop foot.

\section{HASIL PENELITIAN}

Hasil uji normalitas dengan kolmogorove smirnove diketahui bahwa nilai Asymp sig kesemuanya > 0,05 dari varibael waktu dan kecepatan pengguna AFO Fleksibel sehingga data terdistribusi normal. Begitu pula pada kelompok $A F O$ Jointed plantar stop diketahui bahwa nilai Asymp sig kesemuanya > 0,05 dari varibael waktu dan kecepatan pengguna AFO Jointed plantar stop sehingga data terdistribusi normal.karena data terbukti terdistribusi normal maka dapat dilanjutkan uji komparasi dengan menggunakan uji t test perpasangan. 
Tabel 1

Pengaruh AFO Fleksibel Terhadap Waktu Dan Kecepatan Berjalan Pada Penderita Drop Foot

\begin{tabular}{|c|c|c|c|c|}
\hline Variabel & $\begin{array}{c}\text { Perlaku } \\
\text { an }\end{array}$ & Mean & $\mathrm{t}$ & $\begin{array}{c}p \\
\text { valu } \\
e\end{array}$ \\
\hline Time & $\begin{array}{l}\text { Pretest } \\
\text { Postest }\end{array}$ & $\begin{array}{l}79,303 \\
73,400\end{array}$ & $\begin{array}{c}13,43 \\
9\end{array}$ & $\begin{array}{c}0,00 \\
0\end{array}$ \\
\hline Variabel & $\begin{array}{l}\text { Perlaku } \\
\text { an }\end{array}$ & Mean & $\mathrm{T}$ & $\begin{array}{c}p \\
\text { valu } \\
e\end{array}$ \\
\hline $\begin{array}{c}\text { Kecepata } \\
n\end{array}$ & $\begin{array}{l}\text { Pretest } \\
\text { Postest }\end{array}$ & $\begin{array}{l}0,380 \\
0,411\end{array}$ & $\begin{array}{c}- \\
13,17 \\
1\end{array}$ & $\begin{array}{c}0,00 \\
0\end{array}$ \\
\hline
\end{tabular}

a. Pengaruh $A F O$ Fleksibel terhadap waktu berjalan penderita drop foot

Hasil penelitian menunjukkan ratarata pretest waktu berjalan penderita drop foot $(79,330)$ sedangkan rata-rata postest $(73,400)$. Hasil uji statistik dengan $t$ tes perpasangan menunjukkan $(p=0,000)$ sehingga terdapat pengaruh atau perbedaan waktu sebelum menggunakan AFO Fleksibel dengan setalah menggunakan AFO Fleksibel.

b. Pengaruh $A F O$ Fleksibel terhadap kecepatan berjalan penderita drop foot

Hasil penelitian menunjukkan ratarata pretest kecepatan berjalan penderita drop foot $(0,380)$ sedangkan rata-rata postest $(0,411)$. Hasil uji statistik dengan $t$ tes perpasangan menunjukkan $(p=0,000)$ sehingga terdapat pengaruh atau perbedaan kecepatan sebelum menggunakan AFO Fleksibel dengan setalah menggunakan AFO Fleksibel.
Tabel 2

Pengaruh AFO Jointed Plantar Stop Terhadap Waktu Dan Kecepatan Berjalan Penderita Drop Foot

\begin{tabular}{ccccc}
\hline Variabel & $\begin{array}{c}\text { Perlaku } \\
\text { an }\end{array}$ & Mean & $\mathrm{t}$ & $\begin{array}{c}p \\
\text { valu } \\
e\end{array}$ \\
\hline Time & Pretest & 79,303 & 11,80 & 0,00 \\
& Postest & 75,270 & 2 & 0 \\
\hline Variabel & Perlaku & Mean & $\mathrm{T}$ & $\begin{array}{c}p \\
\text { valu } \\
\end{array}$ \\
& an & & & $e$ \\
\hline $\begin{array}{c}\text { Kecepata } \\
\text { n }\end{array}$ & Pretest & 0,380 & 11,19 & 0,00 \\
& Postest & 0,401 & 8 & 0 \\
\hline
\end{tabular}

a. Pengaruh AFO Jointed plantar stop terhadap waktu berjalan penderita drop foot

Hasil penelitian menunjukkan ratarata pretest waktu berjalan penderita drop foot $(79,330)$ sedangkan rata-rata postest $(75,270)$. Hasil uji statistik dengan $t$ tes perpasangan menunjukkan $(p=0,000)$ sehingga terdapat pengaruh atau perbedaan waktu sebelum menggunakan AFO Jointed plantar stop dengan setalah menggunakan AFO Jointed Plantar Stop.

b. Pengaruh penggunaan AFO Jointed Plantar Stop terhadap kecepatan berjalan penderita drop foot

Hasil penelitian menunjukkan ratarata pretest kecepatan berjalan penderita drop foot $(0,380)$ sedangkan rata-rata postest $(0,401)$. Hasil uji statistik dengan $t$ tes perpasangan menunjukkan $(p=0,000)$ sehingga terdapat pengaruh atau perbedaan kecepatan sebelum menggunakan AFO Jointed Plantar Stop dengan setalah menggunakan $A F O$ Jointed Plantar stop. 
Tabel 3

Perbandingan Afo Fleksibel Denagn Afo Jointed Plantar Stop Terhadap Waktu Dan Kecepatan Berjalan Penderita Drop Foot

\begin{tabular}{ccccc}
\hline Variabel & $\begin{array}{c}\text { Perlaku } \\
\text { an }\end{array}$ & Mean & $\mathrm{t}$ & $\begin{array}{c}p \\
\text { valu } \\
e\end{array}$ \\
\hline Time & & & & \\
Post & & 73,400 & & \\
AFO & Postest & & & 0,01 \\
Fleksibel & & & - & 3 \\
Time & & & & \\
Post & & & & \\
AFO & Postest & 75.270 & & \\
Jointed & & & & \\
Plantar & & & & \\
stop & & & & \\
\hline Kecepata & & & & \\
n Post & & 0,411 & & \\
AFO & Postest & & & \\
Fleksibel & & & & \\
Kecepata & & & & \\
n Post & Postest & & & \\
AFO & & & & \\
Jointed & & & & \\
Plantar & & & & \\
Stop & & & & \\
& & & & \\
\end{tabular}

a. Perbandingan penggunaan $A F O$ Fleksibel dan AFO Jointed plantar stop terhadap waktu berjalan penderita drop foot

Hasil penelitian menunjukkan ratarata postest waktu berjalan menggunakan AFO Fleksibel $(73,400)$ sedangkan ratarata posttest menggunakan AFO Jointed plantar Stop $(75,270)$. Hasil uji statistik dengan $t$ tes perpasangan menunjukkan $(p=0,013)$ sehingga terdapat pengaruh atau perbedaan waktu menggunakan $A F O$ Fleksibel dengan menggunakan $A F O$ Jointed Plantar Stop.

b. Perbandingan penggunaan $A F O$ Fleksibel dan AFO Jointed plantar stop terhadap kecepatan berjalan penderita drop foot

Hasil penelitian menunjukkan ratarata kecepatan berjalan dengan menggunakan AFO Fleksibel postest $(0,411)$. Sedangakan rata - rata kecepatan berjalan menggunakan AFO Jointed plantar stop post test $(0,401)$ Hasil uji statistik dengan $t$ tes perpasangan menunjukkan $(p=0,012)$ sehingga terdapat pengaruh atau perbedaan kecepatan menggunakan AFO Fleksibel dengan setalah menggunakan $A F O$ Jointed plantar stop.

\section{PEMBAHASAN}

a. Pengaruh penggunaan $A F O$ Fleksibel dan AFO Jointed plantar Stop terhadap kecepatan berjalan pada pasien drop foot karena CVA

Hasil penelitian menunjukkan bahwa terdapat pengaruh $A F O$ fleksibel maupun AFO Jointed plantar stop terhadap kecepatan berjalan pada penderita drop foot oleh karena CVA dengan $p$ value $0,000<0,05$. Hal ini diperkuat dari rata-rata pretest kecepatan berjalan penderita drop foot $(0,380)$ sedangkan rata-rata postest $(0,411)$ pada penggunaan $A F O$ fleksibel. Sedangkan rata-rata pretest kecepatan berjalan penderita drop foot $(0,380)$ sedangkan rata-rata postest $(0,401)$ pada penggunaan AFO Jointed Plantar stop.

Hasil penelitian ini juga menunjukan bahwa penggunaan $A F O$ Fleksibel memiliki hasil kecepatan gerak yang lebih bagus bila dibandingkan dengan penggunaan AFO Jointed Plantar Stop pada pasien yang mengalami drop foot oleh karena CVA. Hal ini dapat dilihat dari hasil perbedaan postes antara $A F O$ Fleksibel dengan AFO Jointed 
plantar stop yaitu sebesar 0,411 $0,401=0,010$

Hasil penelitian ini mendukung penelitian dari Sarah F.Tyson (2013) yang menyatakan bahwa penggunaan Ankle Foot Orthosis (AFO), dapat meningkatkan kemampuan berjalan dan keseimbangan yang di tunjukan dengan hasil berupa efek AFO pada aktifitas berjalan $(\mathrm{P}=0.000$ 0.001) dan keseimbangan (distribusi berat $)(\mathrm{P}=0.003)$ yang diartikan terdapat pengaruh penggunaan $A F O$ terhadap aktifitas berjalan dan keseimbangan secara signifikan dan menguntungkan. Penggunaan Ankle Foot Orthosis pada kasus drop foot untuk mencegah terjadinya drop pada kaki, sehingga apabila para penderita drop foot berjalan menggunakan Ankle Foot Orthosis maka terjadinya drop pada kaki dapat terkoreksi dan dapat mencegah terjadinya penyimpangan pola berjalan yang dapat berpengaruh terhadap kemampuan aktifitas berjalan dan keseimbangan.

\section{KESIMPULAN DAN SARAN}

1. Ada pengaruh $A F O$ Fleksibel terhadap kecepatan berjalan penderita drop foot oleh karena CVA dengan $p$ value $0,000<0,05$.

2. Ada pengaruh $A F O$ Jointed plantar stop terhadap kecepatan berjalan penderita drop foot oleh karena CVA dengan $p$ value $0,000<0,05$.

3. Ada perbedaan pengaruh penggunaan AFO Fleksibel dengan AFO Jointed Plantar Stop terhadap kecepatan berjalan penderita drop foot oleh karena CVA dengan selisih 0,010, yang dapat di artikan penggunaan $A F O$ fleksibel lebih baik dapat memberikan efek kecepatan berjalan penderita drop foot oleh karena CVA
4. Bagi masyarakat khususnya penderita drop foot dan orang di sekitarnya perlunya meningkatan pemahaman tentang upaya penanganan kondisi kaki drop foot yang baik dan benar dalam pandangan medis sehingga dapat mencegah kecacatan lebih lanjut dengan konsultasi kepada ahli terapis.

5. Bagi Institusi pendidikan hendaknya berperan untuk memberikan edukasi dan meningkatkan pengetahuan masyarakat tentang peran dan manfaat ortotik prostetik perlu terus ditingkatkan melalui pemberian konsultasi ataupun mengadakan seminar kesehatan.

6. Bagi Praktisi Ortotis Prostetis, hendaknya terus mengadakan inovasi dengan melakukan penelitian tentang manfaat, kelebihan dan kekurangan dari bahan-bahan yang dipilih untuk mengembangkan pengetahuan ortotik prostetik dan pelayanan ortotik prostetik di masyarakat.

\section{DAFTAR RUJUKAN}

Agustina L.2011. Hubungan antara kadar Low Density LippoproteinCholesterol (LDL-C) dengan kejadian gangguan kognitif pada penderita pasca stroke iskemik. Tesis.Semarang. Universitas Diponegoro.

Ambrose TL, Eng JJ. 2015. Exercise Training and Recreational Activities to Promote Executive Functions in Chronic Stroke: A Proof of Concept Study . J Stroke Cerebrovasc Dis. 24 I1):130-7.

Andaka D. 2013. Lesi Hemisfer Kiri Berkorelasi Positif dengan Disfungsi Ereksi pada pasien Pasca Stroke. Tesis. Denpasar. Universitas Udayana. 
Axanditya B. 2014. Hubungan Faktor Resiko Stroke Non Hemoragic dengan Fungsi Motorik. Skripsi. Semarang .Universitas Diponegoro

Balitbang Kemenkes RI.2013. Riset Kesehatan Dasar ; RISKESDAS. Jakarta : Balitbang Kemenkes RI.

CSPO Lecturers (2010); Lower Extremity Orthotics Manual; Foot/Ankle Orthotics (FO/AFO), Cambodian School of Prosthetics\&Orthorics Phnom Penh, Cambodia.

Danovska M, Stamenov B, Alexandrova M, Peychinska D. 2012. Post Stroke Cognitive Impairment Phenomenology and Prognostic Factors. J of IMAB.18

De Quervain, et al. Gait Pattern in the Early Recovery Period after Stroke. The Journal of Bone\& Joint Surgery. 1996; 78:1506-14

Feigin V (2007). Stroke. Panduan Bergmabar Tentang Pencegahan \& Pemulihan Stroke. Jakarta. PT. Bhuana Ilmu Populer pp 9-20

Hedna VS, Bodhit AN, Ansari S, Falchook AD, Stead LG, Bidari S, et al.2013. Admission Motor Strength Grade Predicts Motality in Patients with Acute Ischemic Stroke Undergoing Mechanical Thrombectomy. Neurosci Med. 4 : 1-6

Kulshreshtha A, Anderson LM, Ghoyal A, Keenan NL.2012. Stroke In South Asia : A Systemic Review of Ephidemiologic Literature from 1980 to 2010. Neuroepidemiology. 38 (3):123-9

Lisnaini. 2012. Senam Vitalisasi Otak Dapat Meningkatkan Fungsi Kognitif Usia Dewasa Muda. Jakarta : Universitas Kristen Indonesia
Muttaqin Arif 2008. Buku Ajar Asuhan Keperawatan Klien Dengan Gangguan Sistem Persyarafan. Jakarta : Salemba Medica

Price S.A dan Wilson Lorriane M.C. (2006). Patofisologi Clinical Concepsts of Desiase Process. Edisi 6 Vol 2 Alih bahasa Brahm. U. EGC.Jakarta

Smeltzer C. Suzanne, Brenner \& Suddarth. 2002. Buku Ajar Keperawatan Medical Bedah. EGC.Jakarta

Smeltzer C. Suzanne.dkk.2001. Buku Ajar Keperawatan Medical Bedah (Edisi 8 ). Jakarta : EGC

Suyono, A., 1992; Gangguan Sensori Motor pada Penderita Hemiplegi Pasca Stroke. WorkshopFisioterapi pada Stroke, IKAFI Jakarta.

Von Schroeder, et al. Gait parameters following stroke : A practical assessment. Journal of

Rehabilitation Research and Development Vol . 32 No . 1, February 1995.

Yavuzer, Melek Gunes. 2006. Walking After Stroke: Interventions to restore normal gait pattern. Ankara, Turkey: Pelikan Publications

Yuniarti T.2008. Ensiklopedia Tanaman Obat Tradisional. Cetakan pertama.Yogyakarta.medpress. 